\title{
PP2A inhibitors arrest G2/M transition through JNK/Sp1- dependent down-regulation of CDK1 and autophagy-dependent up-regulation of p21
}

\author{
Fei-Ran Gong ${ }^{1,2,3,4,5, *}$, Meng-Yao Wu ${ }^{1, *}$, Meng Shen ${ }^{1, *}$, Qiaoming Zhi ${ }^{6}$, Ze-Kuan Xu${ }^{7}$, \\ Rong Wang ${ }^{1}$, Wen-Jie Wang ${ }^{1}$, Yang Zong ${ }^{7,8}$, Zeng-Liang Li ${ }^{7}$, Yadi Wu ${ }^{9,11}$, Binhua P. \\ Zhou $^{10,11}$, Kai Chen ${ }^{1}$, Min Tao ${ }^{1,12,13,14}$, Wei Li ${ }^{1,14}$ \\ ${ }^{1}$ Departments of Oncology, the First Affiliated Hospital of Soochow University, Suzhou, China \\ ${ }^{2}$ Departments of Hematology, the First Affiliated Hospital of Soochow University, Suzhou, China \\ ${ }^{3}$ Jiangsu Institute of Hematology, the First Affiliated Hospital of Soochow University, Suzhou, China \\ ${ }^{4}$ Key Laboratory of Thrombosis and Hemostasis of Ministry of Health, the First Affiliated Hospital of Soochow University, \\ Suzhou, China \\ ${ }^{5}$ Collaborative Innovation Center of Hematology, Soochow University, Suzhou, China \\ ${ }^{6}$ Department of General Surgery, the First Affiliated Hospital of Soochow University, Suzhou, China \\ ${ }^{7}$ Department of General Surgery, the First Affiliated Hospital of Nanjing Medical University, Nanjing, China \\ ${ }^{8}$ Department of General Surgery, the Changshu No.1 People's Hospital, Changshu, China \\ ${ }^{9}$ Departments of Molecular and Biomedical Pharmacology, University of Kentucky College of Medicine, Lexington, KY, USA \\ ${ }^{10}$ Departments of Molecular and Cellular Biochemistry, University of Kentucky College of Medicine, Lexington, KY, USA \\ ${ }^{11}$ Markey Cancer Center, University of Kentucky College of Medicine, Lexington, KY, USA \\ ${ }^{12}$ Jiangsu Institute of Clinical Immunology, Suzhou, China \\ ${ }^{13}$ Institute of Medical Biotechnology, Soochow University, Suzhou, China \\ ${ }^{14}$ PREMED Key Laboratory for Precision Medicine, Soochow University, Suzhou, China \\ *These authors have contributed equally to this work
}

Correspondence to:

Wei Li, e-mail: liwei10@suda.edu.cn

Min Tao, e-mail: mtao@medmail.com.cn; e-mail: taomin@suda.edu.cn

Keywords: PP2A, G2/M cell cycle arrest, JNK, CDK1, Sp 1

Received: January 14, $2015 \quad$ Accepted: May 14, $2015 \quad$ Published: May 25, 2015

\section{ABSTRACT}

Protein phosphatase 2A (PP2A) plays an important role in the control of the cell cycle. We previously reported that the PP2A inhibitors, cantharidin and okadaic acid $(O A)$, efficiently repressed the growth of cancer cells. In the present study, we found that PP2A inhibitors arrested the cell cycle at the G2 phase through a mechanism that was dependent on the JNK pathway. Microarrays further showed that PP2A inhibitors induced expression changes in multiple genes that participate in cell cycle transition. To verify whether these expression changes were executed in a PP2Adependent manner, we targeted the PP2A catalytic subunit (PP2AC) using siRNA and evaluated gene expression with a microarray. After the cross comparison of these microarray data, we identified that CDK1 was potentially the same target when treated with either PP2A inhibitors or PP2AC siRNA. In addition, we found that the down-regulation of CDK1 occurred in a JNK-dependent manner. Luciferase reporter gene assays demonstrated that repression of the transcription of CDK1 was executed through the JNK-dependent activation of the Sp1 transcription factor. By constructing deletion mutants of the CDK1 promoter and by using ChIP assays, we identified an element in the CDK1 promoter that responded to the JNK/Sp1 pathway after 


\begin{abstract}
stimulation with PP2A inhibitors. Cantharidin and OA also up-regulated the expression of p21, an inhibitor of CDK1, via autophagy rather than PP2A/JNK pathway. Thus, this present study found that the PP2A/JNK/Sp1/CDK1 pathway and the autophagy/p21 pathway participated in G2/M cell cycle arrest triggered by PP2A inhibitors.
\end{abstract}

\section{INTRODUCTION}

Natural products and their derivatives have shown promising outcomes in cancer therapies. In our previous study, we demonstrated that cantharidin, the active constituent of Chinese blister beetle, [1] inhibited growth of pancreatic and breast cancer cells, [2,3] offering a potential role for cantharidin in cancer treatment. Cantharidin acts as a potent and selective inhibitor of protein phosphatase 2A (PP2A), [4] a multimeric serine/ threonine phosphatase that is generally considered to be a cancer repressor. On one hand, inhibition of PP2A is believed to have tumor-promoting function [5] through induction of phosphorylation and activation of several substrate kinases, including IKK (IKB kinase), JNK (c-Jun N-terminal kinase), ERK (extracellular signalrelated kinase), p38, Akt, and PKC (protein kinase C), most of which accelerate growth. $[6,7]$ On the other hand, recent studies showed that PP2A inhibition by specific inhibitors also elicit growth-suppressive effect through several growth inhibition pathways, [8,9] including the JNK pathway that we reported previously. [2] Inhibition of this pathway significantly reduced the cytotoxic effect of cantharidin and okadaic acid (OA; another classic PP2A inhibitor), [2] suggesting that inhibition of PP2A indeed has tumor suppressive function. Thus, understanding the molecular mechanism underlying the growth-suppressive effect of PP2A inhibition will not only minimize the unwanted side effect of PP2A inhibition but also facilitate the development of PP2A inhibitors (i.e., cantharidin) as new therapeutic agents for cancer treatment.

In our previous study, we found that treatment with PP2A inhibitors arrested G2/M cell cycle transition. [2] However, it remained unknown whether G2/M cell cycle arrest was induced through the JNK pathway dependent manner, and whether G2/M arrest is sufficient to suppress the growth of cancer cells. In the present study, we dissected the detailed signaling mechanisms involved in the G2/M cell cycle arrest and JNK dependent cell-killing effect induced by PP2A inhibitors in pancreatic, breast and lung cancer cells.

\section{RESULTS}

\section{PP2A inhibitors repressed G2/M cell cycle transition}

Dose- and time-dependent repression on cell growth by PP2A inhibitors was firstly confirmed by MTT assay. Pretreatment with SP600125, the classic JNK inhibitor, attenuated the growth repression by PP2A inhibitors, indicating the JNK pathway dependent cytotoxicity of PP2A inhibitors (Figure 1A and Supplementary Figure 1). In order to investigate whether $\mathrm{G} 2 / \mathrm{M}$ cell cycle arrest was also executed through the activation of JNK pathway, we used flow cytometry, based on PI staining, to analyze the cell cycle distribution. As shown in Figure 1B, PP2A inhibitors induced cell accumulation at $\mathrm{G} 2 / \mathrm{M}$ phase in a dose-dependent manner, with concurrent decreases in cell populations at $\mathrm{G} 0 / \mathrm{G} 1$ and $\mathrm{S}$ phases, after $24 \mathrm{~h}$ treatment. The level of G2/M aggregation was reduced by pretreatment with SP600125, suggesting that PP2A inhibitors induced G2/M arrest through a JNK dependent pathway.

As flow cytometry analysis based on PI staining cannot distinguish between G2 and M cell cycle arrest, because cells at both these phases are diploid; flow cytometry analysis based on mithramycin A staining was performed. [10] Colchicine, an established M phase blocker, was used as the positive control for inducing $\mathrm{M}$ phase cell cycle arrest. As shown in Figure 1C, colchicine treated cells became round and detached; and flow cytometry analysis, based on mithramycin A staining, confirmed that the cells accumulated in $\mathrm{M}$ phase. Similarly, cells treated with PP2A inhibitors also became round and detached (Figure 1D). Furthermore, pretreatment with the JNK inhibitor, SP600125, protected cells from this morphological change; however, neither of these treatments induced accumulation of cells in $M$ phase (Figure 1D), which suggested that G2/M cell cycle arrest induced by PP2A inhibitors occurred at G2 phase.

The cell cycle transition is regulated by cyclin, cyclin-dependent kinases (CDKs), and cyclin-dependent kinase inhibitors (CKIs). [11, 12] To investigate which genes were involved in the cell cycle alteration triggered by PP2A inhibitors, we performed microarray analyses to determine the mRNA expressions of 72 genes participating in cell cycle regulation. Among these genes, expression changes of 21 genes consist with the decreases in cell populations at $\mathrm{G} 0 / \mathrm{G} 1$ and $\mathrm{S}$ phases, as well as arrested G2/M transition in both cantharidin and OA treated groups (Figure 1E), suggesting multiple genes were involved in the cell cycle regulation by PP2A inhibitors.

\section{PP2A inhibitors repressed cell growth through JNK dependent downregulation of CDK1}

Previous study proved that PP2A inhibitors also present an inhibition effect on PP1 (protein phosphatase 1). [13] To investigate whether these expression changes of cell cycle related genes were executed through a PP2A inhibition dependent manner, we applied siRNA targeting PP2A catalytic subunit $\alpha$ isoform (PP2Ac $\alpha$ ) [14] to get 

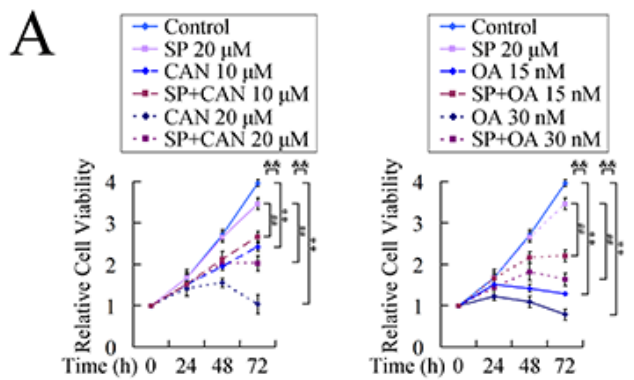

$\mathrm{E}$
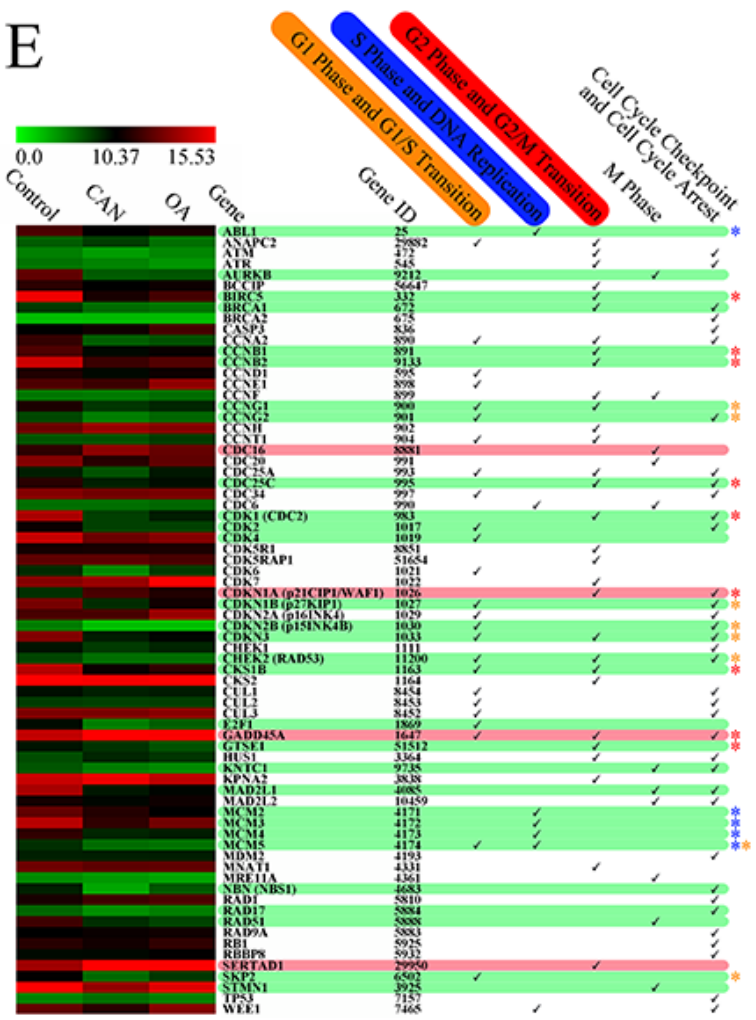

B
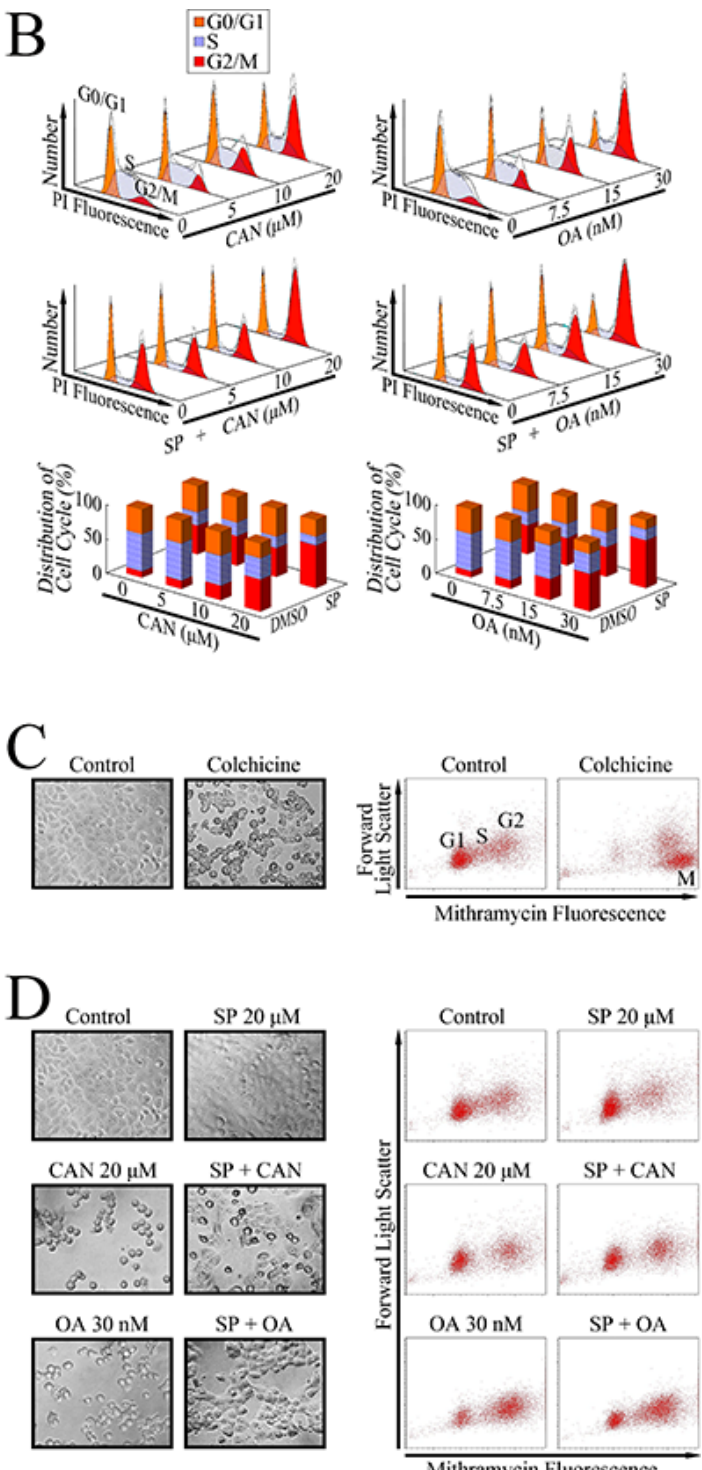

Figure 1: G2/M cell cycle arrest in PANC-1 cells after PP2A inhibitor treatment. A. Growth curve of cantharidin (CAN), and okadaic acid $(\mathrm{OA})$ treated cells, with or without the pretreatment with JNK inhibitor, SP600125 (SP). ${ }^{* *} P<0.01$ vs. respective control groups; ${ }^{\#} P<0.01$ vs. SP600125 group; ${ }^{\&} \& P<0.01$ induction between groups. B. DNA histogram and cell cycle distribution after treatment with cantharidin and OA, pretreated with or without SP600125. C. Photomicrographs of Colchicine treated cells $(\times 40)$; and flow cytometry analyses based on mithramycin A staining. D. Photomicrographs of PP2A inhibitors and JNK inhibitor-treated cells $(\times 40)$; and flow cytometry analyses based on mithramycin A staining. E. Illustration of the microarrays results. Up-regulated genes were highlighted in red below, and down-regulated genes were highlighted in green below. The differences in expression changes reached more than 2-fold are marked with colored * (yellow, genes involved in the regulation of G1 phase and G1/S cell cycle transition; blue, genes involved in the regulation of S phase; red, genes involved in the regulation of $\mathrm{G} 2$ phase and $\mathrm{G} 2 / \mathrm{M}$ cell cycle transition).

a specific PP2A inhibition and tested mRNA expression profile by using microarray. Knockdown of PP2Ac $\alpha$ was firstly confirmed by real-time PCR (Figure 2A). As $\alpha$ and $\beta$ isoforms of PP2Ac share similar coding sequence, [15] we also tested the expression of PP2Ac $\beta$. As presented in Figure $2 \mathrm{~A}$, expression of $\mathrm{PP} 2 \mathrm{Ac} \beta$ was also repressed by PP2Ac $\alpha$ siRNA. By using primers targeting both $\alpha$ and $\beta$ isoforms, we confirmed the knockdown of total PP2Ac expression (Figure 2A), which resulted in the downregulation of PP2Ac at protein level (Figure 2B).
Upon PP2Ac was knockdown, mRNA expression profile was evaluated by using microarray. The expression profiles upon treatment with PP2Ac $\alpha$ siRNAs or PP2A inhibitors were pairwise compared. As shown in Figure 2C, Spearman's rank correlation analysis revealed that the mRNA expression values correlated significantly, suggesting the changes of expression profiles upon PP2A inhibitor treatment were mainly through inhibition on PP2A.

After cross comparison of the expressions of cell cycle related genes upon treatment with PP2A inhbitors 
A
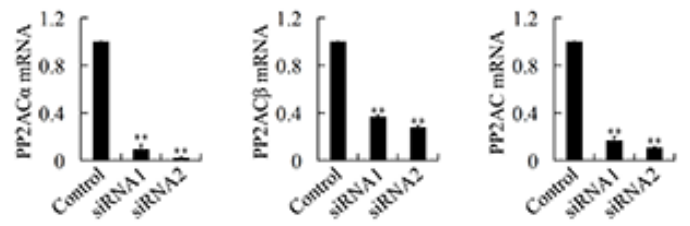

$\mathrm{D}$
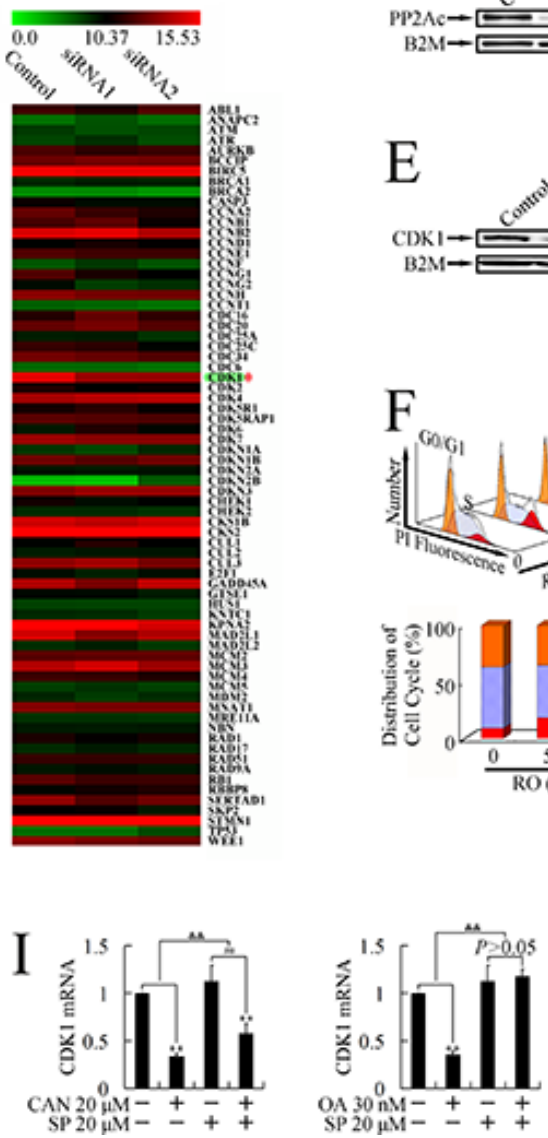
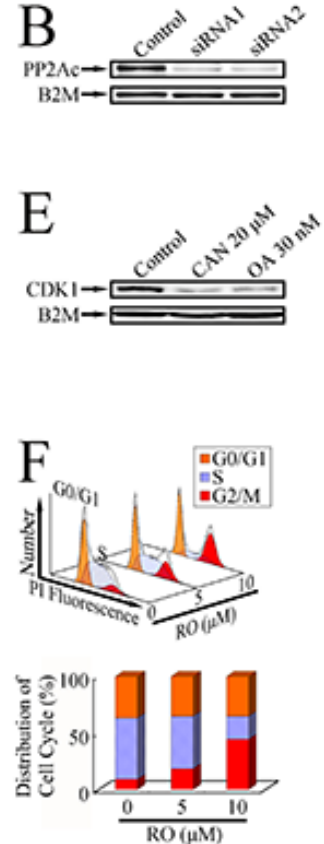

$\mathrm{C}$
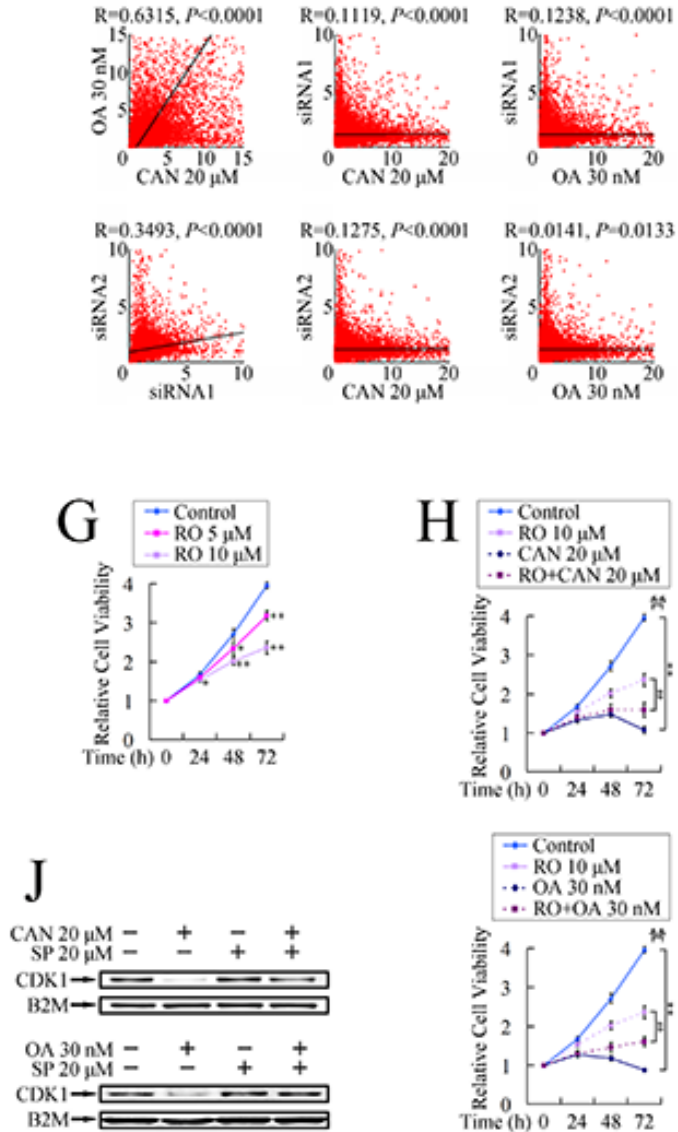

$\mathrm{K}$
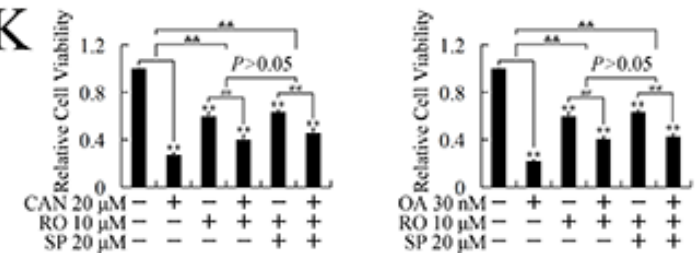

Figure 2: Identification of CDK1 as the target gene at the downstream of PP2A/JNK pathway upon treatment with PP2A inhibitors in PANC-1 cells. A. and B. Confirmation of knockdown of PP2Ac by using real-time PCR (A) and western blot (B). C. Pairwise comparison of gene expression profiles upon treatments with cantharidin (CAN), OA and PP2Ac $\alpha$ siRNAs by using spearman's rank correlation analysis. D. Illustration of the microarrays results. E. Confirmation of down-regulated CDK1 upon treatment with PP2A inhibitors by using western blot. F. DNA histogram and cell cycle distribution after treatment with RO-3306. G. Growth curve of RO-3306 treated cells. $* P<0.05, * * P<0.01$ vs. control group. H. Growth curve of cantharidin, and OA treated PANC-1 cells, with or without the pretreatment with RO-3306. ${ }^{* *} P<0.01$ vs. respective control groups; ${ }^{\#} P<0.01$ vs. RO-3306 group; ${ }^{*} P<0.01$ induction between groups. I. and J. After pretreatment with the JNK inhibitor, SP600125, for $3 \mathrm{~h}$, PP2A inhibitors were added into the culture, and cells were treated for $24 \mathrm{~h}$. (I) Real-time PCR and (J) Western blotting were used to evaluate mRNA levels and protein levels of CDK1, respectively. K. The effect of pretreatment with SP600125 shows no difference from cotreatment with RO-3306. $* * P<0.01$ vs. respective control groups; ${ }^{\#} P<0.01$ vs. RO-3306 group or SP600125 group; ${ }^{\&} P<0.01$ induction between groups.

and PP2Ac siRNAs, we identified that CDK1, the key regulator of $\mathrm{G} 2 / \mathrm{M}$ cell cycle transition, [16] was the unique $\mathrm{G} 2 / \mathrm{M}$ cell cycle regulator, which share the same tendence in all treated groups (Figure 2D and Figure 1E), suggesting the repression on CDK1 could be executed through PP2A inhibition dependent manner.
The down-regulation of CDK1 by PP2A inhibitor treatment was further confirmed at protein level by western blot (Figure 2E). To investigate the role of CDK1 in PANC-1 cell cycle transition and cell growth, cells were treated with RO-3306, a CDK1 inhibitor, and cell cycle assay and MTT assay were performed. As shown 
in Figure 2F and 2G, RO-3306 dose-dependently arrested cell cycle in $\mathrm{G} 2 / \mathrm{M}$ phase and repressed cell growth in both dose-and time-dependent manner, suggesting CDK1 plays an important role in PANC-1 cell growth. Furthermore, pretreatment with RO-3306 impaired the cytotoxicity of PP2A inhibitors (Figure 2H), suggesting CDK1 downregulation participated in the cytotoxicity induced by PP2A inhibitors.

To define the relationship between JNK pathway activation and CDK1 down-regulation, we pretreated cells with SP600125 and evaluated mRNA and protein levels of CDK1 upon treatment with PP2A inhibitors. As shown in Figure 2I, 2J and Supplementary Figure 2, the downregulation of CDK1 could be reversed by pretreatment with JNK inhibitor, suggesting that down-regulation of CDK1 was through a JNK dependent pathway. Pretreatment with RO-3306 impaired the protection effect of JNK inhibitor against the cytotoxicity of PP2A inhibitors (Figure 2K), suggesting the JNK pathway dependent growth inhibition and G2/M cell cycle arrest could be executed through down-regulation of CDK1.

Thus, the PP2A/JNK/CDK1 cell signaling transition pathway dependent G2/M cell cycle arrest could be involved in the mechanism of cytotoxicity induced by PP2A inhibitors.

\section{PP2A inhibitors repressed CDK1 expression through activation of Sp1 transcriptional factor}

To investigate the mechanisms involved in JNK dependent down-regulation of CDK1, we cloned the CDK1 promoter [17, 18] into the pGL3-Basic luciferase reporter vector and tested its transcriptional activity after PP2A inhibition. As shown in Figure 3A, treatment with PP2A inhibitors repressed the transcriptional activity of the CDK1 promoter. Conversely, repression was attenuated by pretreatment with SP600125, the JNK inhibitor, which suggested that JNK dependent down-regulation of CDK1 was executed through repression of CDK1 transcription.

The transcriptional factor, Sp1, is a primary target of the JNK pathway; [19-24] therefore, we used luciferase reporter vectors containing the known $\mathrm{Sp} 1$ binding sites, GGGCGG or GGGGCGGGGC, to investigate whether Sp1 was involved in the JNK dependent down-regulation of CDK1. As shown in Figure 3B, Sp1 was activated after treatment with PP2A inhibitors; whereas pretreatment with SP600125 repressed Sp1 activation, indicating that PP2A inhibitors induced Sp1 activation through a JNK dependent pathway.

We next investigated whether repression of the CDK1 promoter, down-regulation of CDK1, and inhibition of cell growth, which were induced by PP2A inhibitors, were executed through Sp1 activation dependent manner. Real-time PCR using target specific siRNAs confirmed knockdown of $\mathrm{Sp} 1$ (Figure 3C). Luciferase reporter gene assays proved that interference of $\mathrm{Sp} 1$ attenuated repression of the CDK1 promoter (Figure 3D); real-time PCR confirmed down-regulation of CDK1 expression (Figure 3E); and MTT assays confirmed inhibition of cell growth (Figure 3F). These results suggested that PP2A inhibitors induced G2/M cell cycle arrest and repressed cell growth through the PP2A/JNK/Sp1/CDK1 pathway.

\section{Identification of the CDK1 promoter region which responded to the PP2A/JNK/Sp1 pathway}

Activated Sp1 can either be a transcriptional activator or a repressor, depending on the stimulation, cell type, and target DNA. [25] In this study, Sp1 acted as a transcriptional activator when bound to the known Sp1 binding sites, but behaved as a transcriptional repressor when bound to the CDK1 promoter; therefore we attempted to identify the region of the CDK1 promoter that responded to $\mathrm{Sp} 1$ when treated with PP2A inhibitors.

The CDK1 promoter deletion constructs used for the transient transfection analysis are illustrated in Figure 4A. A significant increase of luciferase activity was observed when the base pairs between -382 and -372 were deleted, suggesting this region might contain the element that responded to PP2A inhibitor treatment (Figure 4B). The JNK inhibitor had no influence on the change in transcriptional activity induced by PP2A inhibitors when this region ( -382 to $-372 \mathrm{bp}$ ) was deleted (Figure 4C); but attenuated transcriptional repression when this region was present (Figure 4D). This suggested that PP2A inhibitors decreased CDK1 transcription through JNK pathway dependent repression of the CDK1 promoter region between -382 and $-372 \mathrm{bp}$.

ChIP assays were performed to confirm the binding of Sp1 to this promoter region. As shown in Figure 4E, binding of Sp1 to this region was increased by treatment with PP2A inhibitors, but attenuated by pretreatment with the JNK inhibitor, suggesting that JNK dependent repression of this promoter region was mediated through transcriptional factor Sp1. Because no known Sp1 binding sites were found in this region, this indicated indirect binding between $\mathrm{Sp} 1$ and this region.

\section{PP2A inhibitors repressed cell growth through PP2A/JNK pathway independent and autophagy dependent up-regulation of $\mathbf{p} 21$}

In our previous study, we have proved that expression of p21, the key inhibitor of CDK1, [11, 12] was upregulated upon treatment with PP2A inhibitors; [2] however, the mechanisms involved were unclear. By using microarray, we found that the down-regulation of p21 could be induced by cantharidin and OA (Figure 1E), but did not present when treated with PP2Ac $\alpha$ siRNAs (Figure 2D), suggesting cantharidin and OA repressed p21 expression through a PP2A independent manner. To further verify whether activation of JNK pathway participated in the down-regulation of 

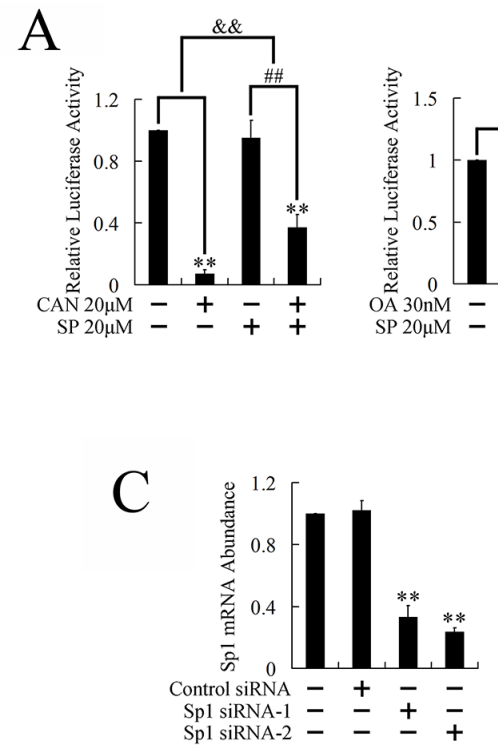

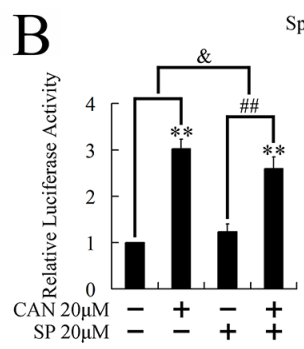

Sp-1-luc (1)
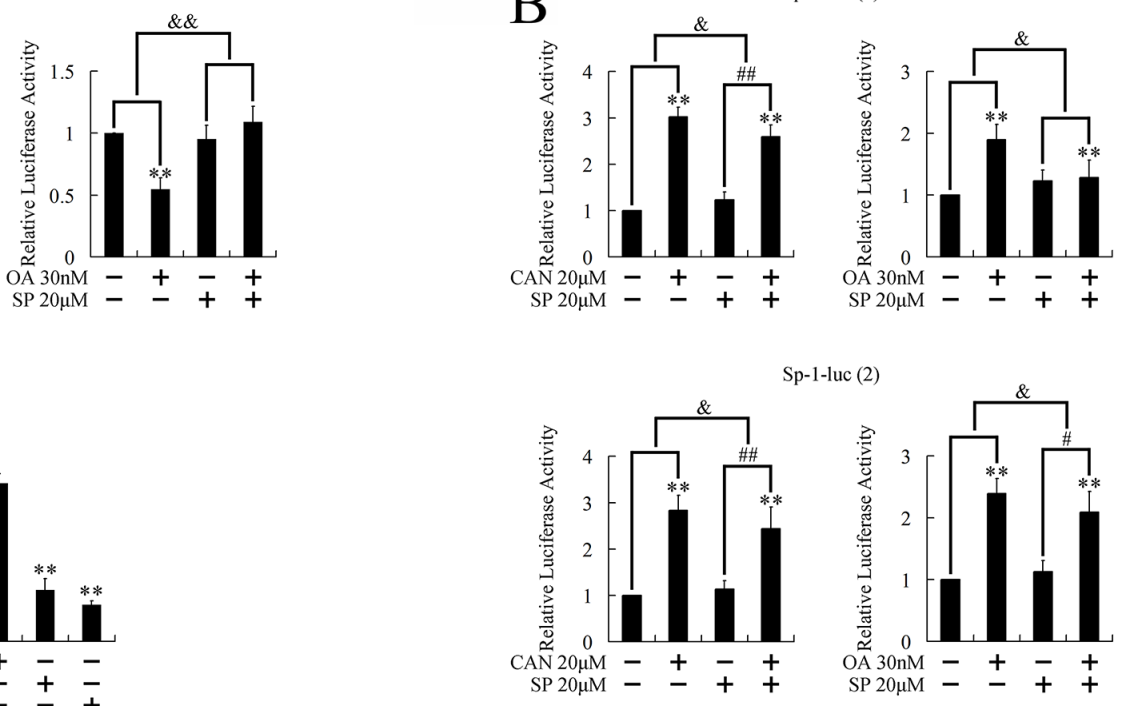
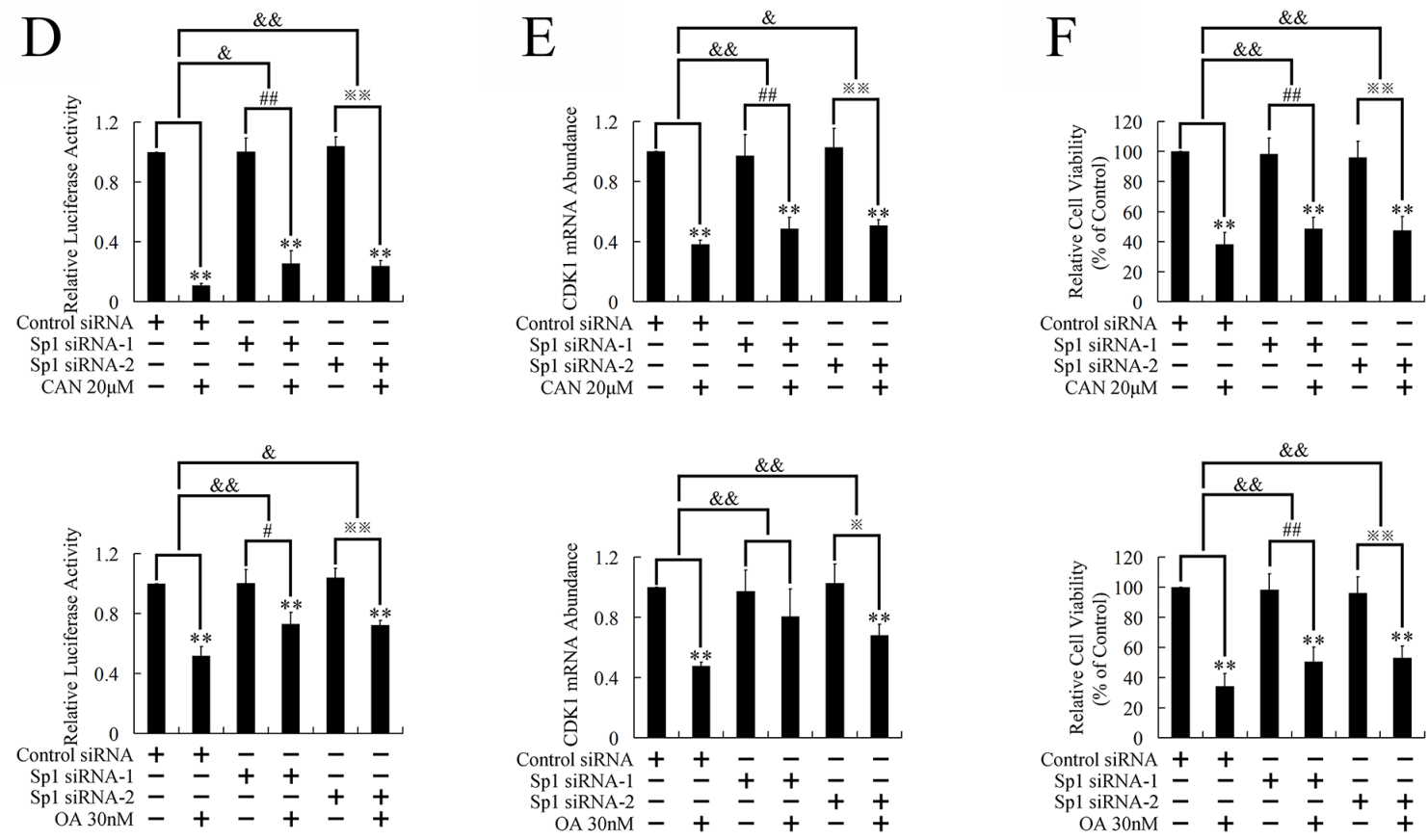

Figure 3: Involvement of transcriptional factor Sp1 in the JNK/CDK1 dependent cytotoxicity of PP2A inhibitors against PANC-1 cells. A. Transcriptional activity of CDK1 promoter after treatment with PP2A inhibitors: after co-transfection with a reporter plasmid containing the CDK1 promoter and an internal plasmid; cells were pretreated with SP600125 for $3 \mathrm{~h}$, followed by PP2A inhibitor treatment for $36 \mathrm{~h}$; the cells were then harvested and luciferase reporter gene assays were performed. $* * P<0.01$ vs. respective control groups; ${ }^{\#} P<0.01$ vs. SP600125 group; ${ }^{\& \&} P<0.01$ induction between groups. B. Transcriptional activation of Sp1 by PP2A inhibitors: cells were first co-transfected with a reporter plasmid containing repeating Sp1 binding sites and an internal plasmid; cells were then pretreated with SP600125, followed by PP2A inhibitor treatment for $36 \mathrm{~h}$ before the luciferase reporter gene assays were performed. ** $P<0.01 \mathrm{vs.}$ respective control groups; ${ }^{\#} P<0.05$ and ${ }^{\#} P<0.01$ vs. SP600125 group; ${ }^{\&} P<0.05$ induction between groups. C. Real-time PCR analysis of Sp1mRNA levels after transfection with Sp1-siRNA for $24 \mathrm{~h} .{ }^{* *} P<0.01$ vs. control group. D. Knockdown of Sp1 attenuated repression of the CDK1 promoter: the reporter plasmid containing CDK1 promoter and the pRL-SV40 plasmid were co-transfected $24 \mathrm{~h}$ after transfection with Sp1-siRNA; cells were then treated with PP2A inhibitors for 36 h, followed by luciferase assay. E. Knockdown of Sp1 attenuated the downregulation of CDK1 expression: after transfection with Sp1-siRNA for $24 \mathrm{~h}$, cells were treated with PP2A inhibitors for a further $24 \mathrm{~h}$; CDK1 expression was evaluated by Real-time PCR. F. Knockdown of Sp1 attenuated the inhibition of cell growth: after transfection with Sp1-siRNA for $24 \mathrm{~h}$, cells were treated with PP2A inhibitors for a further $24 \mathrm{~h}$; cell viability was determined by MTT assay. ** $P<0.01$ vs. respective control groups; ${ }^{\#} P<0.05$ and ${ }^{\# \#} P<0.01$ vs. Sp1-siRNA groups; ${ }^{\&} P<0.05$ and ${ }^{\& \&} P<0.01$ induction between groups. 
A

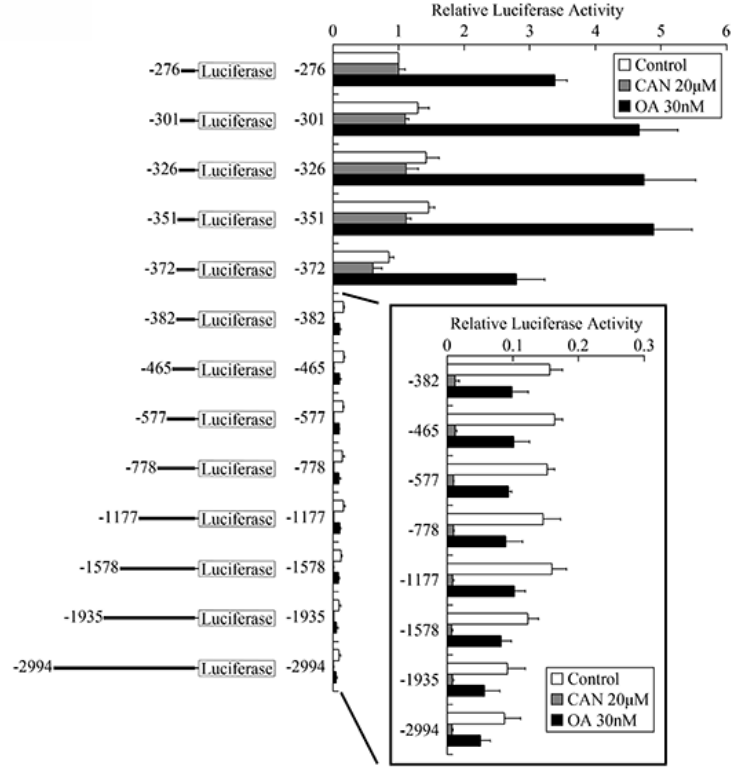

B

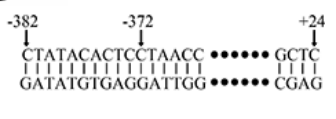

C
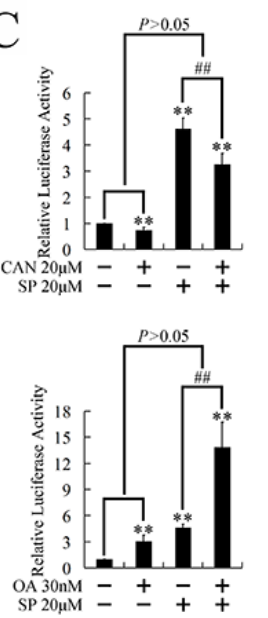
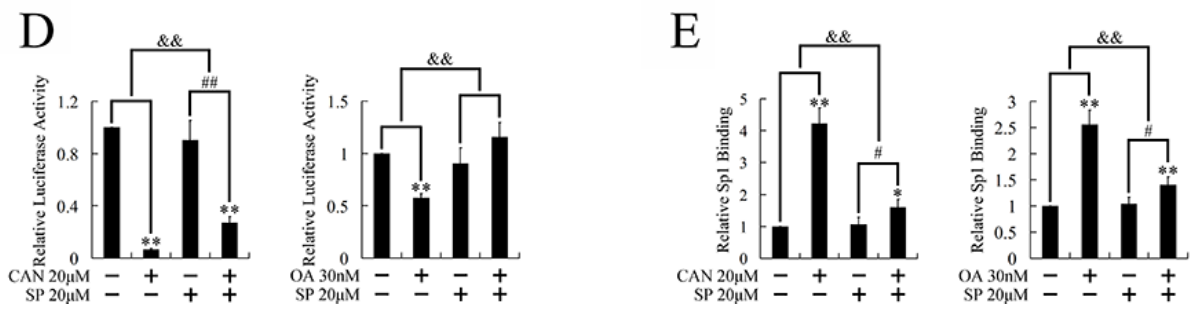

Figure 4: Identification of the CDK1 promoter regions which responded to PP2A inhibitors in PANC-1 cells. A. Schematic diagram of the CDK1 promoter deletions created in the luciferase reporter construct, and the relative luciferase activities derived from the deletion constructs when transfected into PANC-1 cells. Cells were treated with PP2A inhibitors for $36 \mathrm{~h}$ after transfection and before the luciferase gene reporter assays were performed. The activity of the $-276 \sim+24$ bp construct was given a value of 1 , and the activities of the other transfections were normalized to this value. B. Sequence of the responsive element. C. JNK independent regulation of the activity of the $-372 \sim+24$ bp construct; D. JNK dependent regulation of the activity of the $-382 \sim+24$ bp construct, after treatment with PP2A inhibitors: after transfection, cells were treated with the JNK inhibitor for $3 \mathrm{~h}$, and then treated with PP2A inhibitors for $36 \mathrm{~h}$, followed by the luciferase gene reporter assays. E. JNK dependent regulation of binding between $\mathrm{Sp} 1$ and the responding element: cells were pretreated with SP600125 for $3 \mathrm{~h}$, and then treated with PP2A inhibitors for $36 \mathrm{~h}$, followed by the ChIP assays. $* P<0.05$ and $* * P$ $<0.01$ vs. respective control groups; ${ }^{\#} P<0.05$ and ${ }^{\#} P<0.01$ vs. SP600125 group; ${ }^{\&} P<0.05$ and ${ }^{\& \&} P<0.01$ induction between groups.

p21, we pretreated cells with SP600125 and evaluated p21 expression after treatment with cantharidin and OA. As shown in Figure 5A, 5B and Supplementary Figure 3, both the expression of $\mathrm{p} 21$ were up-regulated after PP2A inhibitor treatment; however, pretreatment with SP600125 had no repression on the level of up-regulation, suggesting that $\mathrm{p} 21$ up-regulation was not through PP2A/JNK pathway.

In our previous study, we demonstrated that autophagy induction could arrest G2/M cell cycle transition through up-regulation of p21. [26] In the present study, we tried to investigate whether this mechanism could also be involved. By using the DsRed-LC3 reporter, the increased formation of LC3 punctate was observed following the treatment with cantharidin and $\mathrm{OA}$ (Figure 5C and
Supplementary Figure 4), suggesting these reagents induces autophagy in cancer cells. Pretreatment with 3-MA (3-Methyladenine), a classic autophagy inhibitor, attenuated or even reversed the stimulation on $\mathrm{p} 21$ expression by OA and cantharidin (Figure 5D and Supplementary Figure 5), suggesting the increased p21 expression was executed through an autophagy dependent manner.

To find out whether the up-regulation of p21 contributed to the cytotoxicity of cantharidin and OA, we used siRNA targeting p21 to block the p21 mediated effect on cell growth. Knockdown of p21 by siRNA was firstly confirmed by real-time PCR (Figure 5E). As shown in Figure 5F, knockdown of p21 impaired the repression on cell growth by cantharidin and OA, suggesting the 

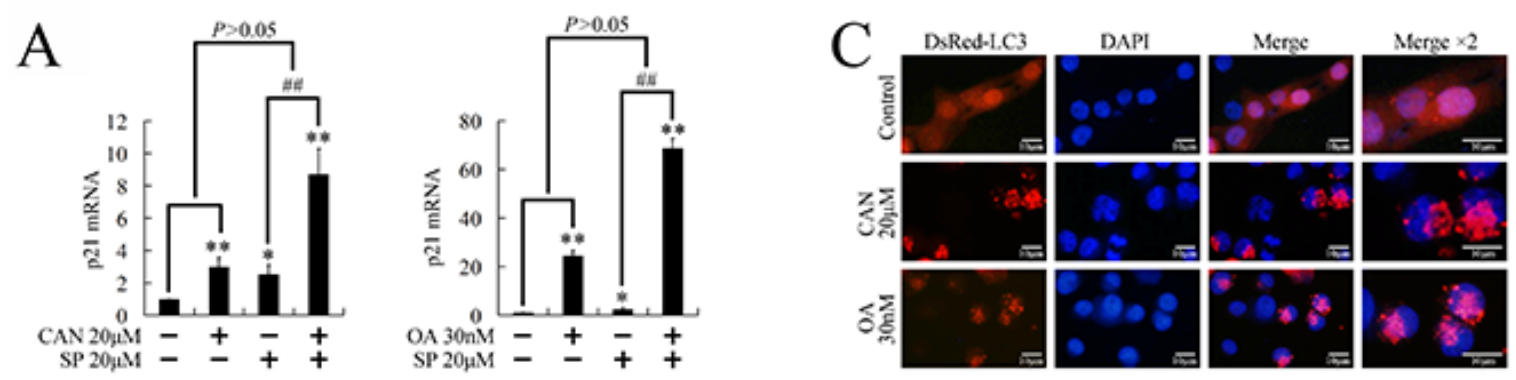

$\mathrm{B}$

$\mathrm{E}$
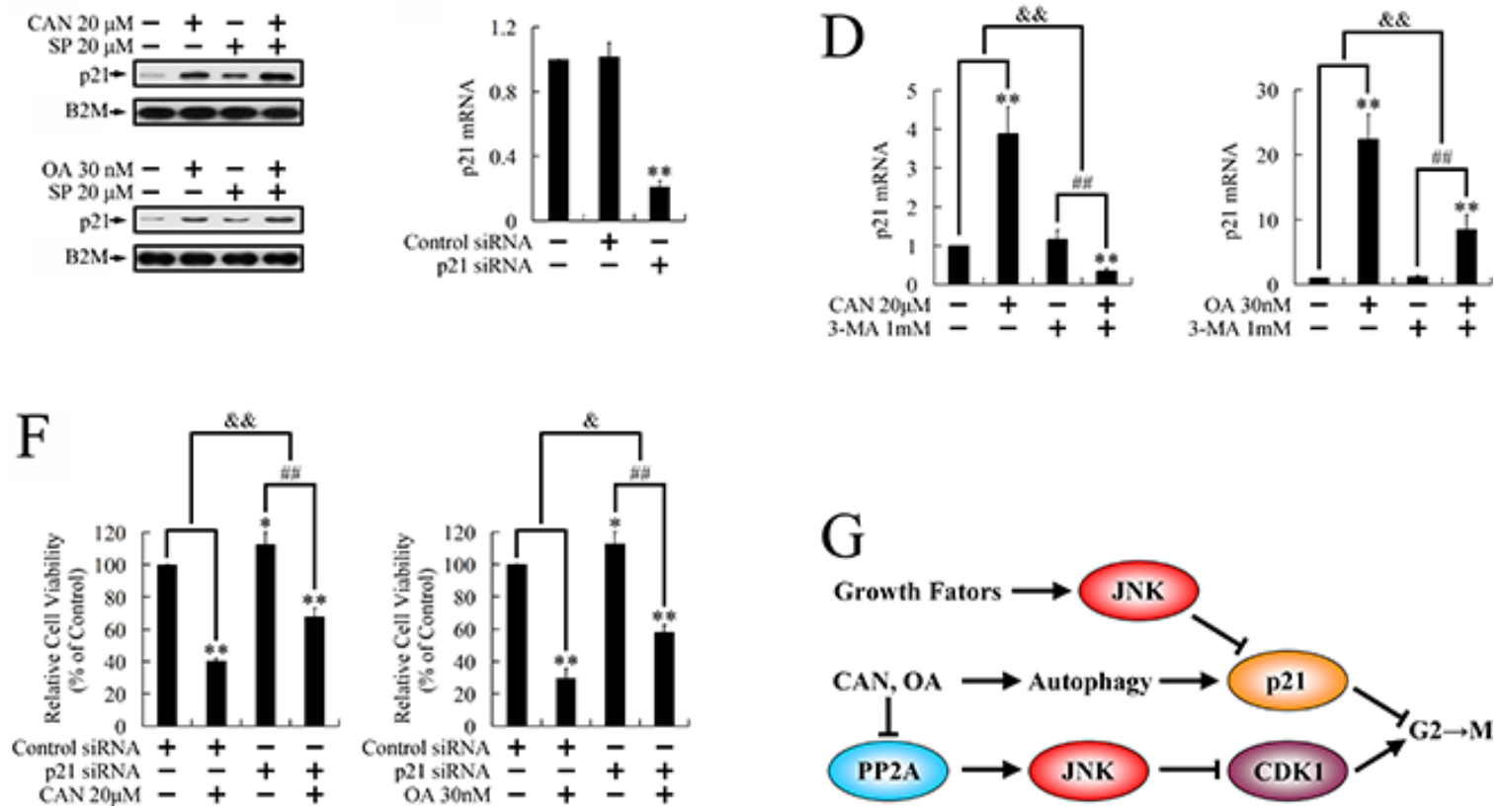

Figure 5: Regulation of p21 expression by cantharidin and OA in PANC-1 cells. A. Real-time PCR and B. Western blotting were used to evaluate mRNA levels and protein levels of p21 after treatment with cantharidin or OA for $24 \mathrm{~h}$, with or without pretreatment with SP600125. C. Formation of LC3 punctate after treatment with cantharidin or OA for $24 \mathrm{~h}$. D. Real-time PCR was performed to evaluate mRNA levels of p21 after treatment with cantharidin or OA for $24 \mathrm{~h}$, with or without pretreatment with 3-MA. E. Real-time PCR was used to confirm down-regulated mRNA levels of p21 after transfection with p21-siRNA for $24 \mathrm{~h}$. F. After transfection with p21-siRNA for $24 \mathrm{~h}, \mathrm{PP} 2 \mathrm{~A}$ inhibitors were added into the culture, and cells were treated cells for $48 \mathrm{~h}$. Cell growth was evaluated by MTT assay. $* P<$ $0.05, * * P<0.01$ vs. respective control groups; ${ }^{\#} P<0.01$ vs. SP600125 group; ${ }^{\&} P<0.05$, \&\& $P<0.01$ induction between groups. G. Cell signaling pathways involved in the present study.

autophagy dependent stimulation of p21 also participated in the cytotoxicity of cantharidin and OA.

\section{DISCUSSION}

JNK is a kinase that is evolutionarily conserved in eukaryotes. [27] In our previous studies, the JNK pathway was found to be overactivated by treatment with PP2A inhibitors, $[2,28]$ which led to JNK dependent repression of cell growth. $[2,28]$ In this study, we focused on cell cycle regulation by the JNK pathway, and proved that PP2A inhibitors arrested the cell cycle at G2 phase through a JNK dependent manner.
The specificity of PP2A inhibitors has always been questioned for its slight inhibition effect on PP1 [13]. By using microarray, we confirmed that cantharidin and OA share extremely similar effects on expression on target genes. By using Spearman's rank correlation analysis, we found out that gene expression profiles of both cantharidin and OA were significantly correlated with PP2Ac knockdown groups. Thus, the present study proved the effects of PP2A inhibitors were mainly fulfilled through inhibition on PP2A, and both cantharidin and $\mathrm{OA}$ are reliable tools for investigation of PP2A. By using microarray, we identified that CDK1, the key regulator of $\mathrm{G} 2 / \mathrm{M}$ cell cycle transition was 
up-regulated by PP2A inhibitors or PP2Ac $\alpha$ targeting siRNAs. For the first time, we have found that the expression of CDK1 could be regulated by JNK pathway, and that growth inhibition of PP2A inhibitors was through the JNK/CDK1 pathway.

$\mathrm{Sp} 1$ is a zinc finger transcription factor that belongs to the $\mathrm{Sp} /$ Kruppel-like factors (KLF) family, characterized by their affinity for GC-rich promoter sequences, and is a major downstream target of the JNK pathway. [19-24] Sp1 has been shown to regulate the expression of thousands of genes involved in wide range of cellular processes, such as proliferation, growth, differentiation, and angiogenesis; $[29,30]$ therefore, we investigated whether the JNK dependent repression of CDK1 was mediated through Sp1. By using luciferase reporter gene assays, we demonstrated that PP2A inhibitors induced JNK upregulation of transcription at DNA sequences containing known Sp1 binding sites. This indicated that $\mathrm{Sp} 1$ was activated through the PP2A/JNK pathway; however, transcription of CDK1 was also repressed, suggesting that regulation of Sp1 transcription was target specific.

Post-translational modifications of Sp1 have been implicated in the regulation of $\mathrm{Sp} 1$. For example, phosphorylation, glycosylation, sumoylation, acetylation, and ubiquitination regulate $\mathrm{Sp} 1$ stability in a proteasomedependent manner; [19, 31,-33] in addition, phosphorylation regulates the DNA binding and transcriptional activity of Sp1. [25] The following studies have proved that JNK plays an important role in the post-translational modification of $\mathrm{Sp} 1$ : JNK activation is necessary to phosphorylate $\mathrm{Sp} 1$, $[19,23,24]$ and to shield Sp1 from the ubiquitin-dependent degradation pathway; [19] knockdown or inhibition of JNK induced dephosphorylation resulted in the ubiquitination and degradation of Sp1; [19-23] phosphorylation of Sp1 by JNK was found to promote DNA binding [34] and transcription in some studies, [24, 35] but repress DNA binding [23] in other studies. Interestingly, okadaic acid (OA) was found to increase the level of Sp1 phosphorylation [36-38] and prevent Sp1 degradation in a JNK dependent way; [39] in addition, OA induced phosphorylation of Sp1 either promotes $[38,40]$ or represses [36] DNA binding, depending on the stimulation and target DNA. These data suggest that the post-translational modification of Sp1 may be involved in the transcriptional repression of CDK1 upon treatment with PP2A inhibitors.

Although no typical Sp1 binding sites were found in the DNA sequence that responded to the PP2A/ JNK pathway, ChIP assays confirmed the interaction between $\mathrm{Sp} 1$ and the responsive element of the CDK1 promoter, which indicated indirect binding of $\mathrm{Sp} 1$ to this DNA region. A number of studies have demonstrated that post-translational modifications both regulate the intracellular compartmentalization of $\mathrm{Sp} 1$ and modulate its interactions with other transcription factors. [41-43] There are compelling data to indicate that the Sp1dependent activation and repression of target promoters is modulated by its interactions with a repertoire of heterogeneous transcriptional regulators. A partial list of Sp1-interacting proteins includes the Mediator complex, c-Myc, Ah, Arnt, ER, AR, GATAs, p53, MEF2C, Smad2-4, Msx1, Rb, NF-кB, NF-YA, VHL, MyoD, E2F, NFAT-1, and YY1; [41] however, which transcriptional regulator participated in the regulation of $\mathrm{Sp} 1$ in the responsive element of the CDK1 promoter remains to be verified.

Microarray data also indicated a PP2A independent regulation on $\mathrm{p} 21$ by cantharidin and $\mathrm{OA}$. Consisting with this result, the PP2A inhibition dependent activation of JNK had no effect on p21 expression, although the basal activity of JNK represses p21 expression, which might promote mitosis. $[28,44]$ This data suggested that in the normal culture environment, JNK dependent repression on $\mathrm{p} 21$ promoted cell growth. While in the circumstance of treatment with PP2A inhibitors, overactivation of JNK inhibited cell growth through repression on CDK1 (Figure 5G).

The PP2A/JNK independent repression on $\mathrm{p} 21$ was further proved to be related to autophagy induction. Autophagy is a genetically programmed, evolutionarily conserved process that degrades long-living cellular proteins and organelles, including the endoplasmic reticulum, Golgi apparatus, and mitochondria. [45] During autophagy the cytoplasmic constituents are delivered to the lysosome, forming a double-membrane vesicle, termed as autophagosome. [46] There is an increasing interest in exploring autophagy as a mechanism of action in cancer therapy. By now, 16 autophagy-related proteins (Atg proteins) have been identified to participate in autophagy. [47] LC3, the mammalian ontology of Atg8, is a credible marker for the autophagosome. [47, 48] During formation of autophagosomes, LC3 will form punctate structures within the cytoplasm that correspond to autophagic vesicles. [47]

Recent studies have explored the connection between PP2A and autophagy. PP2A can exert both a positive and negative effect on autophagy, depending on the particular step on which it acts and on its composition in subunits. [49] However, based on our present study, specific knockdown of PP2Ac did not affect the expression of $\mathrm{p} 21$. While treatment with cantharidin and OA stimulated p21 expression through autophagy dependent manner, suggesting the autophagy induced by cantharidin and OA might be executed through a PP2A inhibition independent manner.

In conclusion, our previous study had found that PP2A inhibitors activated the JNK pathway, induced G2/M cell cycle arrest, and inhibited growth in cancer cells. This study suggested that the PP2A/JNK/Sp1/CDK1 cell signaling pathway and autophagy/p21 pathway may be responsible for the G2/M cell cycle arrest and cytotoxicity by treatment with PP2A inhibitors in cancer cells (Figure 5G). These data 
also explained the bidirectional mechanism of JNK regulation in cell proliferation: the basal activity of JNK accelerated proliferation through repression of $\mathrm{p} 21$; whereas, overactivated JNK repressed cell growth through upregulation of CDK1.

PP2A is always considered to be a cancer repressor. [5] Previous efforts mostly focused on upregulating $\mathrm{PP} 2 \mathrm{~A}$ to achieve an inhibition on its cancer promoting substrate kinases. [7] So it was really difficult to accept PP2A inhibitors in cancer treatment. Quite on the contrary, the dried body of mylabris, from which cantharidin is extracted, has been used as a traditional Chinese medicine for more than 2000 years and is still being used as a folk medicine. [1] Ancient Chinese applied this natural product to the treatment of cancer with the notion of "fighting fire with fire" [50] without awareness of its molecular target, PP2A. Thus, exploring the mechanism involved in the PP2A-inhibition dependent cytotoxicity, may bring new lights to cancer treatment. Our studies suggest that the PP2A/JNK pathway locates at the crossroad of determining cell fate. To maintain a normal cell function, the activity of PP2A/ JNK pathway must be restricted at an appropriate level, as both repression and overactivation on this pathway could result in growth inhibition. This phenomenon fits well with the 'Yin-Yang' theory, which is an ancient Chinese philosophy nowadays accepted around the world. $[51,52]$ The principle of Yin and Yang, the balance between opposing natural forces, has been emphasised as a fundamental property of cellular growth regulation. [52] Therefore, anti-cancer approaches through activation or repression on PP2A, could both be considered as disturbing the balance between Yin and Yang. And the bidirectional JNK transducts this signal, resulting in cell growth inhibition. Our investigations bring a new cancer treatment strategy by turning a cancer-promoting kinase into an anti-cancer kinase through inhibition of PP2A, providing a whole new way to fight cancer.

\section{MATERIALS AND METHODS}

\section{Cell line and cultures}

The human pancreatic cancer cell line PANC-1, breast cancer cell lines, T-47D and MCF-7, and lung cancer cell lines, NCI-H292 and NCI-H1650, were purchased from the American Type Culture Collection (ATCC, VA, USA). PANC-1 cells were maintained in Dulbecco's minimum essential medium (DMEM; Gibco, NY, USA), while T-47D, MCF-7, NCI-H292 and NCI-H1650 cells were maintained in RPMI-1640 medium (Gibco), supplemented with 10\% fetal calf serum (FCS; Hyclone, UT, USA), 100 units/ $\mathrm{ml}$ penicillin, and $100 \mathrm{mg} / \mathrm{ml}$ streptomycin. The cultures were incubated at $37^{\circ} \mathrm{C}$ in a humidified atmosphere with $5 \% \mathrm{CO}_{2}$. Cells were passaged every $2-3$ days to obtain exponential growth.

\section{Reagents}

Cantharidin, okadaic acid (OA), SP600125, and RO3306 were purchased from Enzo Life Science International (PA, USA). 3-Methyladenine (3-MA) was purchased from Sigma (Sigma, MO, USA).

\section{Cell cycle analysis (PI staining)}

Cell cycle analysis using propidium iodide (PI) was performed as previously described. [2] Prior to treatment, cells were synchronized in the cell cycle by serum starvation for $24 \mathrm{~h}$. [53] After treatment, the cells were fixed in $80 \%$ ice cold ethanol, and incubated with $0.5 \%$ Triton X-100 solution containing $1 \mathrm{mg} / \mathrm{ml}$ RNase $\mathrm{A}$ at $37^{\circ} \mathrm{C}$ for $30 \mathrm{~min}$. PI (Sigma) was added to a final concentration of $50 \mu \mathrm{g} / \mathrm{ml}$ followed by $30 \mathrm{~min}$ incubation in the dark. Cellular DNA content was analyzed by a fluorescence-activated cell sorter (FACS; Becton Dickinson, NJ, USA). Data were processed by ModFit LT software (Verity Software House, ME, USA).

\section{Cell cycle analysis (mithramycin A staining)}

Cell cycle analysis with mithramycin A was performed according to the protocol established by Schmidt et al. [10] Briefly, the cells were incubated with $0.1 \%$ nonidet P-40 for $5 \mathrm{~min}$, followed by fixation with $1 \%$ formaldehyde. Mithramycin A (Sigma) was added to the sample to a final contraction of $20 \mathrm{mg} / \mathrm{ml}$. The green fluorescence of mithramycin A was analyzed by FACS (Becton Dickinson).

\section{MTT assay}

Cellular growth was evaluated by MTT (3-[4, 5-dimethyltiazol-2-yl] 2, 5-diphenyl-tetrazolium bromide) assay. [54] Cells were seeded into 24-well tissue culture plates at $5 \times 10^{4}$ cells per well. After treatment, MTT (Sigma) was added to each well to a final concentration of $0.5 \mathrm{mg} / \mathrm{ml}$, followed by incubation at $37^{\circ} \mathrm{C}$ for $4 \mathrm{~h}$. The medium was then removed, and $600 \mu$ of dimethyl sulfoxide (DMSO) was added per well. As the PP2A inhibitor-treated cells became detached, the formazana in the medium was harvested by centrifugation at 10,000 rpm for $10 \mathrm{~min}$, dissolved in $200 \mu \mathrm{l}$ of DMSO, and then returned to the original well. The absorbance of total $800 \mu$ f formazana dissolved DMSO in each well was measured at $490 \mathrm{~nm}$ using a microplate ELISA reader (Bio-Rad Laboratories, CA, USA). The relative cell viability was calculated as follows: relative cell viability $=$ (mean experimental absorbance/mean control absorbance) $\times 100 \%$.

\section{Real-time PCR}

Total RNA was extracted using Trizol reagent (Invitrogen, CA, USA) according to the manufacturer's protocol. After spectrophotometric quantification, $1 \mu \mathrm{g}$ 
total RNA in a final volume of $20 \mu$ was used for reverse transcription with PrimeScript RT Reagent Kit (TaKaRa, Otsu, Shiga, Japan) according to the manufacturer's protocol. Aliquots of cDNA corresponding to equal amounts of RNA were used for quantification of mRNA by real-time PCR using the LightCycler 96 Real-time Quantitative PCR Detection System (Roche, Indianapolis, IN, USA). The reaction system $(25 \mu \mathrm{l})$ contained the corresponding cDNA, forward and reverse primers, and SYBR Green PCR master mix (Roche). All data were analyzed using B2M gene expression as an internal standard. The specific primers were as follows: (1) p21, forward, 5'-GGACCTGTCACTGTC TTGTACC-3', reverse, 5'-TTCCTGTGGGCGGATT AG-3', product, $177 \mathrm{bp}$; (2) CDK1, forward, 5'-CTAGAAAGTGAA GAGGAAGGGGTT-3', reverse, 5'-CCATGTACTGACCAG GAGGGAT-3', product, 193 bp; (3) Sp1, forward, 5'-CAGTTGGCAGACTCTACA GC-3', reverse, 5'-TCATGTATTCCATCAC CACC-3', product, 345 bp; (4) PP2Ac, forward, 5'-GTTCACCAAGGAGCTGGAC CA-3', reverse, 5'-C ATGCACATCTCCACAGACAGT AAC-3', product, 164 bp; (5) PP2Aco, forward, 5'-CGCCAGAAGTACACGAGGAAC-3', reverse, 5'-CGTT GGATTCTTTTGTCAGGATTT-3', product, 240 bp; (6) PP2Ac $\beta$, forward, 5'-GGGAAACCTGCCTTTGTAT-3', reverse, 5'-CATCATTAGTATGGCACATTTGGTC-3', product, $156 \mathrm{bp}$; and (7) B2M, forward, 5'-TCAAGAA GGTGGTGAAGCAG-3', reverse, 5'-AAGGTGGAGGAG TGGGTGTC-3', product, 112 bp.

\section{Transfection of small interfering RNA}

\begin{abstract}
Target specific small interfering RNAs (siRNAs) were designed and synthesized by Genepharma (Shanghai, China). The specific sequences were as follows: (1) Control-siRNA, sense, 5'-UUCUCCGAACGUGUCACGUdTdT-3', anti-sense, 5'-ACGUGACACGUUCGGAGAAdT dT-3'; (2) p21siRNA, sense, 5'-GACCAUGUGGACCUGUCACd TdT-3', anti-sense, 5'-GUGACAGGUCCACAU GGUC dTdT-3'; (3) Sp1-siRNA-1, sense, 5'-CCAGCAACAUGG GAAUUAUdTdT-3', anti-sense, 5'-AUAAUUCCCAUG UUGC UGGdTdT-3'; (4) Sp1-siRNA-2, sense, 5'-GCCGU UGGCUAUAGCAAAUdTdT-3', anti-sense, 5'-AUUUGC UAUAGCCAACGGCdTdT-3'; (5) PP2Ac $\alpha$-siRNA-1, sense, 5'-CGUGCAAGAGGUUCGAUGUdTdT-3', antisense, 5'-ACAUCGAACCUCUUGCACGdTdT-3'; (6) PP2 Ac $\alpha$-siRNA-2, sense, 5'-GGCAGAUCUUCUGUCUA CAdTdT-3', anti-sense, 5'-UGUAGACAGAAGAUCU GCCdTdT-3'. The transfections were performed with siRNA-Mate Transfection Reagent (Genepharma) according to the manufacturer's protocol.
\end{abstract}

\section{Western blot analysis}

Rabbit anti-CDK1 was purchased from Cell Signaling Technology (MA, USA). Rabbit anti-p21, mouse anti-PP2Ac, and mouse anti-B2M antibodies were purchased from Santa Cruz Biotechnologies (Santa Cruz, CA, USA). Total protein was extracted using a lysis buffer containing $50 \mathrm{mM}$ Tris- $\mathrm{HCl}$ (pH 7.4), $150 \mathrm{mM} \mathrm{NaCl}, 1 \%$ Triton X-100, 0.1\% SDS, 1 mM EDTA, supplemented with protease inhibitors $(10 \mathrm{mg} / \mathrm{mL}$ leupeptin, 10 $\mathrm{mg} / \mathrm{mL}$ aprotinin, $10 \mathrm{mg} / \mathrm{mL}$ pepstatin $\mathrm{A}$, and $1 \mathrm{mM}$ 4-[2-aminoethyl] benzenesulfonyl fluoride). The protein extract was loaded onto an SDS-polyacrylamide gel, size-fractionated by electrophoresis, and then transferred to polyvinylidene fluoride (PVDF) membranes (BioRad Laboratories). After blocking in 5\% non-fat milk for $1 \mathrm{~h}$, the membranes were incubated overnight with primary antibodies at $4^{\circ} \mathrm{C}$. The protein expression was determined using horseradish peroxidase-conjugated antibodies followed by enhanced chemiluminescence (ECL, Millipore, St Charles, MO, USA) detection. The intensity of the bands was captured by JS-1035 image analysis scanning system (Peiqing Science \& Technology, Shanghai, China). B2M was used as the internal control.

\section{Luciferase reporter gene plasmids}

A series of deletion mutants of the human cdk1 promoter $[17,18]$ spanning -2994 to +24 were generated by PCR using pairs of primers bearing specific restriction sites (Table 1), and subcloned into KpnI and XhoI sites of the pGL3-basic vector. The luciferase reporter plasmid, Sp1luc (1), which contains the sequence 5'-CGCGT $\underline{\text { GGGCGG }}$ AACTGGGCGG AGTTAGGGGCGG GA-3', consisting of three consensus Sp1 binding sites (GGGCGG) from the SV40 promoter, was generated by subcloning the above fragment into the NheI and HindIII sites of the pGL3-basic vector, according to Sowa et al. [55] A further TransLucent Sp1 reporter [Sp1-Luc (2)], which contains the sequence 5'-ATTCGATCGGGGCGGGGC GAGATTAGATTCGATCGGGGCGGGGCGAG-3', consisting of two consensus Sp1 binding sites (GGGGCGGGGC), was purchased from Panomics (CA, USA). The internal control plasmid, pRL-SV40, which contained the renilla luciferase gene was obtained from Promega (Madison, WI, USA).

\section{Luciferase reporter gene assay}

Cells were transiently co-transfected with the reporter plasmid (500 ng/well) and the internal control plasmid, pRLSV40 plasmid (100 ng/well) for $6 \mathrm{~h}$ using Lipofectamine 2000 (Invitrogen), according to the manufacturer's protocol. The medium was renewed, and the treatments were initiated. After treatment, the cell lysates were subjected to the dual luciferase reporter assay (Promega) according to the manufacturer's recommendations. The luciferase activities were measured using the GloMax-20/20 luminometer (Promega). The results were expressed as relative luciferase activity (the ratio of firefly luciferase activity to renilla luciferase activity). 
Table 1: Sequences of the oligonucleotide pairs used by PCR to produce deletion mutants covering the CDK1 promoter. KpnI (GGTACC) and XhoI (CTCGAG) sites were added to the primers to direct subcloning, and are italicized and underlined. Positions of the DNA fragments relative to the transcription start site are indicated.

\begin{tabular}{|c|c|c|}
\hline $\begin{array}{l}\text { Position of DNA } \\
\text { fragment }\end{array}$ & Sense $5^{\prime} \rightarrow 3^{\prime}$ & Anti-sense $5^{\prime} \rightarrow 3^{\prime}$ \\
\hline-2994 to +24 & AT GGTACCGATCTCCTGACAACGTGA & CTTTGAAGCCAAGCTCGAGCAGTTT \\
\hline-1935 to +24 & ACGGTACCAGCGGTAACTGTATCTT & CTTTGAAGCCAAG $\underline{C T C G A G C A G T T T}$ \\
\hline-1578 to +24 & ACAGCCT $\underline{G G T A C C C T A G A G C A C T T C}$ & CTTTGAAGCCAAG $\underline{C T C G A G C A G T T T}$ \\
\hline-1177 to +24 & TGGATT GGTACCATGTCTAGCTCTGTTT & CTTTGAAGCCAAG $\underline{C T C G A G C A G T T T}$ \\
\hline-778 to +24 & TTTAAT $\underline{G T T A C C T A A G C C A G G C G T G}$ & CTTTGAAGCCAAG $\underline{C T C G A G C A G T T T}$ \\
\hline-577 to +24 & GCCGGTACCATAAACAAAATGTAAATA & CTTTGAAGCCAAGCTCGAGCAGTTT \\
\hline-465 to +24 & GCGGTACCTTGAGTTTTCCATTTCCT & CTTTGAAGCCAAGCTCGAGCAGTTT \\
\hline-382 to +24 & AA $\underline{G G T A C C T A T A C A C T C C T A A C C C T A A G T ~}$ & CTTTGAAGCCAAGCTCGAGCAGTTT \\
\hline-372 to +24 & CC $\underline{G G T A C C T A A C C C T A A G T A T T A G A A G T}$ & CTTTGAAGCCAAG $\underline{C T C G A G C A G T T T}$ \\
\hline-351 to +24 & TT GGTACCGAAAGTAATGGAATCTC & CTTTGAAGCCAAGCTCGAGCAGTTT \\
\hline-326 to +24 & ATCTCGA GGTACCCACAATATCACTTT & CTTTGAAGCCAAG $\underline{C T C G A G C A G T T T}$ \\
\hline-301 to +24 & AAACACAATATCACTTTTTT $\underline{G T A C C T A}$ & CTTTGAAGCCAAGCTCGAGCAGTTT \\
\hline-276 to +24 & TTTGAACGGTACCAATGCTGGGAGAA & CTTTGAAGCCAAGCTCGAGCAGTTT \\
\hline
\end{tabular}

\section{ChIP assay}

ChIP assays were performed using the ChIP assay kit (Upstate Biotechnology, NY, USA) as previously described. [56] Briefly, Cells $\left(1 \times 10^{7}\right)$ were fixed in medium containing $1 \%$ formaldehyde for $10 \mathrm{~min}$ at room temperature. After cell lysis, genomic DNA was sheared into 200-1000 bp fragments using Sonics VCX130 (Sonics \& Materials, CT, USA). Sheared chromatin was incubated with anti-Sp1 or negative control IgG (Upstate Biotechnology) overnight at $4^{\circ} \mathrm{C}$. $\mathrm{NaCl}$ was added to the ChIP samples for $4 \mathrm{~h}$ at $65^{\circ} \mathrm{C}$ to reverse the cross-links. To purify the immunoprecipitated DNA the following steps were performed: RNase and proteinase $\mathrm{K}$ were added in order; followed by phenol-chloroform extraction; ethanol precipitation; and resuspension of the DNA in distilled water. The purified DNA was further used as a template for real-time PCR detection using an ABI Prism 7500 sequence detection system (Applied Biosystems, CA, USA). The specific primers were as follows: forward, 5'-CCTTTACATTTTTGAGGCGGTC-3', reverse, 5'-CTCCCAGCATTGGCACAGTT-3', product, 229 bp. Real-time PCR data were analyzed as previously described. [56]

\section{Microarray assay}

Sample preparation and processing procedure were performed as described in detail in the Agilent GeneChip Expression Analysis Manual (Santa Clara, CA). Differentially expressed genes were screened using
Agilent 44K human whole-genome oligonucleotide microarrays. The selection criterion was defined as a more than 2-fold difference in the level of expression (difference in up-regulated expression more than 2-fold, and difference in down-regulated expression less than 0.5 -fold). Hierarchical clustering of samples was done by average linkage algorithm using TIGR MultiExperiment Viewer (The Institute for Genomic Research, Rockville, MD, USA).

\section{Autophagy assay using the DsRed-LC3 reporter}

To develop an autophagy reporter, we fused the LC3 (also known as ATG8) cDNA to the C terminus of DsRed as previously described. [57] To produce stable cell lines continuously reporting autophagy activity, recombinant lentiviruses expressing the DsRed-LC3 reporter were generated and used to infect cells. The LC3 puncta were visualized with an Olympus BX51 microscope (Tokyo, Japan). DNA was counterstained using DAPI (Sigma).

\section{Statistical analysis}

Each experiment was performed a minimum of three times. Results were expressed as the mean value \pm standard deviation (SD). Statistical analysis was performed by unpaired Student's $t$-test. The correlations between microarray assays were analyzed using Spearman's rank correlation analysis. A $P$ value $<0.05$ was considered significant. 


\section{ACKNOWLEDGMENTS}

This work was supported by grants from the National Natural Science Foundation of China [Nos. 81472296, 81101867, 81072031, 81272542, 81200369, and 81402477]; the CSPAC-Celgene Foundation; the Natural Science Foundation of Jiangsu Province [No. BK2010585]; China International Medical Foundation [No. CIMF-F-H001-057]; the Medical Scientific Research Project of Jiangsu Provincial Bureau of Health (Z201206); the Special Foundation of Wu Jieping Medical Foundation for Clinical Scientific Research [Nos. 320.6753.1225 and 320.6750.12242]; the Science and Education for Health Foundation of Suzhou for Youth [Nos. SWKQ1003 and SWKQ1011]; the Science and Technology Project Foundation of Suzhou [Nos. SYS201112 and SYSD2012137]; the Science and Technology Foundation of Suzhou Xiangcheng (Nos. SZXC2012-70 and XJ201451); a Project Founded by the Priority Academic Program Development of Jiangsu Higher Education Institutions.

\section{Abbreviations}

PP2A; protein phosphatase 2A, PP2Ac; PP2A catalytic subunit, OA; okadaic acid, JNK; c-Jun $\mathrm{N}$-terminal kinase, CDK; cyclin-dependent kinase, CKI; cyclin-dependent kinase inhibitor, IKK; IкB kinase, ERK; extracellular signal-related kinase, PKC; protein kinase, $\mathrm{C}$ siRNA; small interfering RNA, PP1; protein phosphatase, 1 3-MA; 3-Methyladenine, PI; propidium iodide.

\section{CONFLICTS OF INTEREST}

There are no competing financial interests in relation to this work.

\section{REFERENCES}

1. Wang GS. Medical uses of mylabris in ancient China and recent studies. Journal of ethnopharmacology. 1989; 26:147-162.

2. Li W, Xie L, Chen Z, Zhu Y, Sun Y, Miao Y, Xu Z, Han X. Cantharidin, a potent and selective PP2A inhibitor, induces an oxidative stress-independent growth inhibition of pancreatic cancer cells through G2/M cell-cycle arrest and apoptosis. Cancer science. 2010; 101:1226-1233.

3. Shou LM, Zhang QY, Li W, Xie X, Chen K, Lian L, Li ZY, Gong FR, Dai KS, Mao YX, Tao M. Cantharidin and norcantharidin inhibit the ability of MCF-7 cells to adhere to platelets via protein kinase $\mathrm{C}$ pathway-dependent downregulation of alpha2 integrin. Oncology reports. 2013; 30:1059-1066.

4. Honkanen RE. Cantharidin, another natural toxin that inhibits the activity of serine/threonine protein phosphatases types 1 and 2A. FEBS letters. 1993; 330:283-286.
5. Kurimchak A, Grana X. PP2A Counterbalances Phosphorylation of $\mathrm{pRB}$ and Mitotic Proteins by Multiple CDKs: Potential Implications for PP2A Disruption in Cancer. Genes \& cancer. 2012; 3:739-748.

6. Millward TA, Zolnierowicz S, Hemmings BA. Regulation of protein kinase cascades by protein phosphatase $2 \mathrm{~A}$. Trends Biochem Sci. 1999; 24:186-191.

7. Janssens V, Goris J, Van Hoof C. PP2A: the expected tumor suppressor. Current opinion in genetics \& development. $2005 ; 15: 34-41$.

8. Chen YJ, Kuo CD, Tsai YM, Yu CC, Wang GS, Liao HF. Norcantharidin induces anoikis through Jun-N-terminal kinase activation in CT26 colorectal cancer cells. Anticancer drugs. 2008; 19:55-64.

9. Schweyer S, Bachem A, Bremmer F, Steinfelder HJ, Soruri A, Wagner W, Pottek T, Thelen P, Hopker WW, Radzun HJ, Fayyazi A. Expression and function of protein phosphatase PP2A in malignant testicular germ cell tumours. The Journal of pathology. 2007; 213:72-81.

10. Schmidt M, Lu Y, Liu B, Fang M, Mendelsohn J, Fan Z. Differential modulation of paclitaxel-mediated apoptosis by p21Waf1 and p27Kip1. Oncogene. 2000; 19:2423-2429.

11. van den Heuvel S. Cell-cycle regulation. WormBook : the online review of C elegans biology. 2005; 1-16.

12. Stark GR, Taylor WR. Control of the G2/M transition. Molecular biotechnology. 2006; 32:227-248.

13. Li YM, Casida JE. Cantharidin-binding protein: identification as protein phosphatase 2A. Proceedings of the National Academy of Sciences of the United States of America. 1992; 89:11867-11870.

14. Liu L, Eisenman RN. Regulation of c-Myc Protein Abundance by a Protein Phosphatase 2A-Glycogen Synthase Kinase 3beta-Negative Feedback Pathway. Genes \& cancer. 2012; 3:23-36.

15. Mumby M. PP2A: unveiling a reluctant tumor suppressor. Cell. 2007; 130:21-24.

16. Lorca T, Castro A. Deciphering the New Role of the Greatwall/PP2A Pathway in Cell Cycle Control. Genes \& cancer. 2012; 3:712-720.

17. Badie C, Itzhaki JE, Sullivan MJ, Carpenter AJ, Porter AC. Repression of CDK1 and other genes with CDE and CHR promoter elements during DNA damage-induced G(2)/M arrest in human cells. Molecular and cellular biology. 2000; 20:2358-2366.

18. Dahler AL, Jones SJ, Dicker AJ, Saunders NA. Keratinocyte growth arrest is associated with activation of a transcriptional repressor element in the human cdk1 promoter. Journal of cellular physiology. 1998; 177:474-482.

19. Chuang JY, Wang YT, Yeh SH, Liu YW, Chang WC, Hung JJ. Phosphorylation by c-Jun NH2-terminal kinase 1 regulates the stability of transcription factor Sp1 during mitosis. Molecular biology of the cell. 2008; 19:1139-1151. 
20. Wang SA, Chuang JY, Yeh SH, Wang YT, Liu YW, Chang WC, Hung JJ. Heat shock protein 90 is important for $\mathrm{Sp} 1$ stability during mitosis. Journal of molecular biology. 2009; 387:1106-1119.

21. Kumar D, Hosse J, von Toerne C, Noessner E, Nelson PJ. JNK MAPK pathway regulates constitutive transcription of CCL5 by human NK cells through SP1. J Immunol. 2009; 182:1011-1020.

22. Sroka IC, Nagle RB, Bowden GT. Membrane-type 1 matrix metalloproteinase is regulated by sp1 through the differential activation of AKT, JNK, and ERK pathways in human prostate tumor cells. Neoplasia. 2007; 9:406-417.

23. Chu S, Ferro TJ. Identification of a hydrogen peroxideinduced PP1-JNK1-Sp1 signaling pathway for gene regulation. American journal of physiology Lung cellular and molecular physiology. 2006; 291:L983-992.

24. Benasciutti E, Pages G, Kenzior O, Folk W, Blasi F, Crippa MP. MAPK and JNK transduction pathways can phosphorylate $\mathrm{Sp} 1$ to activate the uPA minimal promoter element and endogenous gene transcription. Blood. 2004; 104:256-262.

25. Chu S, Ferro TJ. Sp1: regulation of gene expression by phosphorylation. Gene. 2005; 348:1-11.

26. Chen K, Shou LM, Lin F, Duan WM, Wu MY, Xie X, Xie YF, Li W, Tao M. Artesunate induces G2/M cell cycle arrest through autophagy induction in breast cancer cells. Anti-cancer drugs. 2014; 25:652-662.

27. Kyriakis JM, Avruch J. Mammalian mitogen-activated protein kinase signal transduction pathways activated by stress and inflammation. Physiological reviews. 2001; 81:807-869.

28. Li W, Chen Z, Gong FR, Zong Y, Chen K, Li DM, Yin H, Duan WM, Miao Y, Tao M, Han X, Xu ZK. Growth of the pancreatic cancer cell line PANC-1 is inhibited by protein phosphatase $2 \mathrm{~A}$ inhibitors through overactivation of the c-Jun N-terminal kinase pathway. Eur J Cancer. 2011; 47:2654-2664.

29. Solomon SS, Majumdar G, Martinez-Hernandez A, Raghow R. A critical role of Sp1 transcription factor in regulating gene expression in response to insulin and other hormones. Life sciences. 2008; 83:305-312.

30. Wierstra I. Sp1: emerging roles - beyond constitutive activation of TATA-less housekeeping genes. Biochemical and biophysical research communications. 2008; 372:1-13.

31. Spengler ML, Brattain MG. Sumoylation inhibits cleavage of Sp1 N-terminal negative regulatory domain and inhibits Sp1-dependent transcription. The Journal of biological chemistry. 2006; 281:5567-5574.

32. Han I, Kudlow JE. Reduced O glycosylation of Sp1 is associated with increased proteasome susceptibility. Molecular and cellular biology. 1997; 17:2550-2558.

33. Su K, Yang X, Roos MD, Paterson AJ, Kudlow JE. Human Sug $1 / \mathrm{p} 45$ is involved in the proteasome-dependent degradation of Sp1. The Biochemical journal. 2000; 348:281-289.
34. Higuchi H, Grambihler A, Canbay A, Bronk SF, Gores GJ. Bile acids up-regulate death receptor 5/TRAIL-receptor 2 expression via a c-Jun N-terminal kinase-dependent pathway involving Sp1. The Journal of biological chemistry. 2004; 279:51-60.

35. Reddy VS, Prabhu SD, Mummidi S, Valente AJ, Venkatesan B, Shanmugam P, Delafontaine P, Chandrasekar B. Interleukin-18 induces EMMPRIN expression in primary cardiomyocytes via JNK/Sp1 signaling and MMP-9 in part via EMMPRIN and through AP-1 and NF-kappaB activation. American journal of physiology Heart and circulatory physiology. 2010; 299:H1242-1254.

36. Armstrong SA, Barry DA, Leggett RW, Mueller CR. Casein kinase II-mediated phosphorylation of the $\mathrm{C}$ terminus of Sp1 decreases its DNA binding activity. The Journal of biological chemistry. 1997; 272:13489-13495.

37. Chu S, Cockrell CA, Ferro TJ. Expression of alpha-ENaC2 is dependent on an upstream Sp1 binding motif and is modulated by protein phosphatase 1 in lung epithelial cells. Biochemical and biophysical research communications. 2003; 303:1159-1168.

38. Vlach J, Garcia A, Jacque JM, Rodriguez MS, Michelson S, Virelizier JL. Induction of Sp1 phosphorylation and NF-kappa B-independent HIV promoter domain activity in T lymphocytes stimulated by okadaic acid. Virology. 1995; 208:753-761.

39. Huang PH, Wang D, Chuang HC, Wei S, Kulp SK, Chen CS. alpha-Tocopheryl succinate and derivatives mediate the transcriptional repression of androgen receptor in prostate cancer cells by targeting the PP2A-JNK-Sp1signaling axis. Carcinogenesis. 2009; 30:1125-1131.

40. Ray A, Schatten H, Ray BK. Activation of Sp1 and its functional co-operation with serum amyloid A-activating sequence binding factor in synoviocyte cells trigger synergistic action of interleukin- 1 and interleukin- 6 in serum amyloid A gene expression. The Journal of biological chemistry. 1999; 274:4300-4308.

41. Safe S, Kim K. Nuclear receptor-mediated transactivation through interaction with Sp proteins. Progress in nucleic acid research and molecular biology. 2004; 77:1-36.

42. Samson SL, Wong NC. Role of Sp1 in insulin regulation of gene expression. Journal of molecular endocrinology. 2002; 29:265-279.

43. Slawson C, Hart GW. Dynamic interplay between O-GlcNAc and O-phosphate: the sweet side of protein regulation. Current opinion in structural biology. 2003; 13:631-636.

44. Hui L, Zatloukal K, Scheuch H, Stepniak E, Wagner EF. Proliferation of human HCC cells and chemically induced mouse liver cancers requires JNK1-dependent p21 downregulation. The Journal of clinical investigation. 2008; 118:3943-3953.

45. Yu HC, Lin CS, Tai WT, Liu CY, Shiau CW, Chen KF. Nilotinib induces autophagy in hepatocellular carcinoma 
through AMPK activation. The Journal of biological chemistry. 2013; 288:18249-18259.

46. Mizushima N. Autophagy: process and function. Genes \& development. 2007; 21:2861-2873.

47. Zhu BS, Xing CG, Lin F, Fan XQ, Zhao K, Qin ZH. Blocking NF-kappaB nuclear translocation leads to p53related autophagy activation and cell apoptosis. World journal of gastroenterology : WJG. 2011; 17:478-487.

48. Chen Y, Azad MB, Gibson SB. Methods for detecting autophagy and determining autophagy-induced cell death. Canadian journal of physiology and pharmacology. 2010; 88:285-295.

49. Cianfanelli V, Fuoco C, Lorente M, Salazar M, Quondamatteo F, Gherardini PF, De Zio D, Nazio F, Antonioli M, D’Orazio M, Skobo T, Bordi M, Rohde M, Dalla Valle L, Helmer-Citterich M, Gretzmeier C, et al. AMBRA1 links autophagy to cell proliferation and tumorigenesis by promoting c-Myc dephosphorylation and degradation. Nature cell biology. 2015; 17:20-30.

50. Wang S, Wu X, Tan M, Gong J, Tan W, Bian B, Chen M, Wang Y. Fighting fire with fire: poisonous Chinese herbal medicine for cancer therapy. Journal of ethnopharmacology. 2012; 140:33-45.

51. Dai MS, Jin Y, Gallegos JR, Lu H. Balance of Yin and Yang: ubiquitylation-mediated regulation of p53 and c-Myc. Neoplasia. 2006; 8:630-644.
52. Pardee AB. The Yang and Yin of cell proliferation: an overview. J Cell Physiol Suppl. 1987; 5:107-110.

53. Kues WA, Anger M, Carnwath JW, Paul D, Motlik J, Niemann H. Cell cycle synchronization of porcine fetal fibroblasts: effects of serum deprivation and reversible cell cycle inhibitors. Biology of reproduction. 2000; 62:412-419.

54. Carmichael J, DeGraff WG, Gazdar AF, Minna JD, Mitchell JB. Evaluation of a tetrazolium-based semiautomated colorimetric assay: assessment of chemosensitivity testing. Cancer research. 1987; 47:936-942.

55. Sowa $Y$, Orita T, Minamikawa S, Nakano K, Mizuno T, Nomura H, Sakai T. Histone deacetylase inhibitor activates the WAF1/Cip1 gene promoter through the Sp1 sites. Biochemical and biophysical research communications. 1997; 241:142-150.

56. Gong F, Sun L, Wang Z, Shi J, Li W, Wang S, Han X, Sun Y. The BCL2 gene is regulated by a special AT-rich sequence binding protein 1-mediated long range chromosomal interaction between the promoter and the distal element located within the 3 '-UTR. Nucleic acids research. 2011; 39:4640-4652.

57. Sheen JH, Zoncu R, Kim D, Sabatini DM. Defective regulation of autophagy upon leucine deprivation reveals a targetable liability of human melanoma cells in vitro and in vivo. Cancer cell. 2011; 19:613-628. 